\title{
Resenha
}

\section{Ensino de tradução, de Sonia Colina: contribuições atuais para a didática da tradução}

José Luiz Vila Real Gonçalves*

COLINA, S. Ensino de tradução: da pesquisa à sala de aula. Diretrizes para professores. Tradução de Marileide Dias Esqueda, Paula Godoi Arbex, Sandra Aparecida Faria de Almeida, Silvana Maria de Jesus e Stéfano Paschoal. Uberlândia: EDUFU, 2015.

A obra Ensino da tradução: da pesquisa à sala de aula. Diretrizes para professores, de Sonia Colina, traduzida por Marileide Dias Esqueda, Paula Godoi Arbex, Sandra Aparecida Faria de Almeida, Silvana Maria de Jesus e Stéfano Paschoal, do original Translation teaching: from research to the classroom. A handbook for teachers, de 2003, traz uma contribuição relevante para as discussões e reflexões, teóricas e práticas, sobre formação de tradutores, suas implicações didático-pedagógicas e a organização de currículos e planos de ensino para cursos de tradução.

A autora é professora da Universidade do Arizona, nos Estados Unidos, nas áreas de linguística e tradução. Seus trabalhos de pesquisa situam-se especialmente entre ensino de tradução, formação de tradutores, ensino de línguas e aquisição de segunda língua, com significativa produção científica nessas áreas.

A tradução para o português, realizada por uma equipe de professores-pesquisadores da Universidade Federal de Uberlândia, destaca-se pela qualidade textual e pelo cuidado terminológico no tocante à área dos Estudos da Tradução, podendo, assim, servir de referência para professores, pesquisadores e tradutores que não tenham o domínio da língua inglesa ou prefiram acessar o texto em língua portuguesa.

O trabalho visa contribuir para os estudos aplicados da tradução, no seu ramo didático, e, consequentemente, para a prática do ensino da tradução, áreas que carecem de maior

\footnotetext{
${ }^{*}$ Universidade Federal de Ouro Preto (UFOP).
} 
investimento, tendo em vista a ainda incipiente e assistemática definição dos parâmetros para a fundamentação e organização dos cursos de formação de tradutores e, por conseguinte, do tão variável perfil do profissional da tradução. Embora a data de publicação do original (2003) tenha um relativo distanciamento temporal da tradução brasileira, deixando assim de incorporar alguns avanços teóricos, didático-pedagógicos e práticos em relação ao campo aplicado dos Estudos da Tradução, o texto tem pertinência e relevância atuais para as discussões na área, com contribuições significativas para o planejamento didático de cursos e disciplinas de tradução. Além disso, mesmo que a obra tenha como ponto de partida o contexto de formação, de pesquisa e profissional estadunidense, as problemáticas abordadas transcendem aquele contexto sociocultural e acadêmico, servindo, pois, para discussões mais gerais da didática da tradução, inclusive apresentando elementos pertinentes para o atual contexto de pesquisa e de formação de tradutores no Brasil.

No prefácio, a autora faz uma apresentação geral da obra, destacando a necessidade de se aprofundarem os estudos voltados para a didática/pedagogia da tradução, tendo em vista o número crescente de cursos de tradução nos Estados Unidos. Nos últimos anos no Brasil, também se criaram novos cursos de formação de tradutores, especialmente em universidades federais. Nesse contexto, muitos dos docentes atuando nesses cursos carecem de uma formação adequada - alguns têm a experiência da prática e do mercado, sem uma formação acadêmica sólida, enquanto outros, advindos do campo da pesquisa, não apresentam um nível razoável de habilidades didáticas e/ou experiência prática no campo profissional. Portanto, Colina enfatiza a necessidade de se articularem os ramos teórico, descritivo e aplicado dos Estudos da Tradução para a consolidação das bases da formação de tradutores, buscando integrar estudos da área da pedagogia com estudos aplicados à metodologia de ensino e formação de professores de tradução e com o desenvolvimento de materiais didáticos e paradidáticos. É destacado que o foco do trabalho se concentra na tradução profissional, em oposição à literária, buscando fundamentar-se em metodologias de pesquisa empírica e tendo como principal referencial teórico as abordagens funcionalistas da tradução, com ênfase nos trabalhos de Nord (1991, 1997). No tocante aos aspectos pedagógicos da tradução, as principais referências adotadas são Kussmaul (1995), Kiraly (1995), Shreve (1997), Cao (1996) e Hatim e Mason (1997). A título de atualização, dentro desse ramo aplicado, é pertinente mencionarmos algumas contribuições mais recentes, citadas e discutidas em trabalhos dentro de temáticas como ensino da tradução, formação de tradutores e competência tradutória, com potencial para dialogar e aprofundar as 
questões propostas por Sonia Colina no trabalho objeto desta resenha, quais sejam Hurtado Albir (2001, 2007, 2008, 2015), PACTE (2003, 2014), Pagano, Magalhães e Alves (2005), Kelly (2005), Galán-Mañas e Hurtado Albir (2010).

No Capítulo 1, Ensino de tradução: da pesquisa à sala de aula, a autora retoma a já mencionada problemática relativa ao ensino da tradução, envolvendo, dentre os principais aspectos: incipiência em relação às bases didático-pedagógicas, metodológicas e epistemológicas, repercutindo na indefinição ou imprecisão dos perfis dos cursos de formação de tradutores; falta de propostas de formação consolidadas para os formadores; adaptação de preceitos aplicados ao ensino de línguas estrangeiras, sem a devida adequação; e falta de materiais didáticos adequados. Assim, a proposta do trabalho é tentar suprir ou, pelo menos, minimizar essas lacunas, criando uma melhor compreensão e articulação entre as questões teóricas e práticas. É dado destaque para as pesquisas empíricas dentro da temática da competência tradutória, tendo em vista seu potencial para o aprofundamento das questões em foco. Ao discutir a inserção do seu trabalho nos Estudos da Tradução, Colina adverte para a necessidade da colaboração e sinergia entre os ramos desse campo disciplinar, ou seja, ela entende ser fundamental que a área de formação dialogue com as pesquisas e com os profissionais atuando no mercado. Além disso, dentro dos ramos de pesquisa, os estudos teóricos, descritivos e aplicados precisam dialogar e se retroalimentar, o que era e é bem pouco observado ainda hoje. Assim, a autora destaca que a obra pode ser usada como referência para discussões paradidáticas na formação de tradutores.

O Capítulo 2, intitulado Fundamentos da pesquisa, apresenta os diversos pilares teóricos utilizados para discutir o ensino de tradução. Inicialmente, abordam-se trabalhos com foco na tipologia textual, nos gêneros textuais e nas funções da linguagem e, em seguida, discutem-se as contribuições da teoria de escopo ou da funcionalidade (HOLZ-MÄNTTÄRI, 1984; REISS; VERMEER, 1984; NORD, 1991, 1997). Tais abordagens representam um avanço na forma como se entende o fenômeno tradutório, uma vez que passam a incluir os aspectos comunicativos e interacionais na tradução, superando, assim, as noções tradicionais de equivalência e correspondência, propostas por modelos centrados nos aspectos formais e estruturais das línguas, que geralmente não consideram a complexidade dos contextos situacionais envolvidos. Destaca-se a importância de pesquisas que utilizam a metodologia de corpus para o desenvolvimento dos estudos descritivos da tradução e a sua contribuição, dentre outras, para o ensino de tradução, com foco na comparação dos aspectos funcionais/contextuais 
entre os textos e as culturas-fonte e alvo. Com base na proposta de análise situacional de textosfonte, de Nord (1997), a autora argumenta que a aplicação de briefs (formulários com questões para a contextualização da tarefa) para os textos-fonte e alvo é de grande importância para a sensibilização do tradutor em formação. Ainda é discutido, nessa primeira seção, o papel das normas e convenções para um entendimento mais preciso dos aspectos funcionais e, portanto, para que se tomem decisões com maior potencial de adequação na produção do texto-alvo. Para a internalização dessas questões pelo tradutor em formação, a autora recomenda que sejam explorados contextos comunicativos autênticos de tradução, como fóruns e listas de discussão virtuais.

Na seção "Pesquisa em pedagogia da tradução", a autora busca confrontar fundamentos teóricos e evidências empíricas para discutir e validar metodologias de ensino de tradução, destacando a importância da pesquisa para o desenvolvimento dos modelos e métodos didáticopedagógicos na formação do tradutor. A competência tradutória é adotada como conceito-chave para se discutirem a caracterização e o desenvolvimento dos conhecimentos e habilidades do tradutor profissional. Assim como diversos outros autores que se dedicam ao tema, Colina argumenta que somente a exposição direta às tarefas e aos contextos de tradução não seria suficiente, ou pelo menos o caminho mais eficiente, para a formação sistematizada e com a devida fundamentação teórica. É destacada também a importância do aprendizado e da prática reflexivos, questões que remetem à discussão sobre o espaço da metacognição na formação e na atuação do tradutor. A título de atualização, verifica-se que as questões da metacognição no ensino de tradução representam tema de grande relevância, como se pode observar em trabalhos como os de Alves, Magalhães e Pagano (2000), Alves e Gonçalves (2007) e Bastin e Cormier (2007).

De forma congruente com as posições de Shreve (1997) e Kiraly (1990), Colina entende que a constituição e o desenvolvimento da competência tradutória dependem de insumos e contextos ricos, ou seja, que deem ênfase aos fatores sociointeracionais. Assim, muito mais que uma faculdade essencialmente cognitiva, a competência tradutória é vista como dependente dos contextos de interação, seja na formação ou na atuação profissional.

A autora aponta a importância da pesquisa empírica para convalidar as proposições teóricas sobre a competência tradutória, reconhecendo, assim, a contribuição de trabalhos que aplicaram a técnica de protocolos verbais na investigação sobre o tema. Há que se ressaltar que hoje temos diversas outras ferramentas e recursos metodológicos, além dos protocolos verbais, 
que têm lançado novas luzes e proporcionado avanços significativos na vertente processual e nos estudos sobre competência tradutória (e.g. JAKOBSEN, 1999; PACTE, 2003; ALVES; GONÇALVES, 2013).

Dentre as várias características distintivas entre o aprendiz e o tradutor profissional, são destacadas as seguintes: o primeiro tende a apresentar um tipo de processamento ascendente, com foco principalmente no léxico, enquanto o profissional destaca-se pelo processamento descendente, global, com foco no sentido, na textualidade e no contexto situacional; e o profissional tende a apresentar maior autoconfiança, autoconsciência e expertise, características a serem observadas na formação do aprendiz. Chegou-se, então, à conclusão de que tais características dos profissionais podem ser favorecidas em um contexto de aprendizagem comunicativo, centrado no aprendiz, em que ele tenha contato com a realidade profissional, especialmente em fóruns e grupos de discussão virtuais. A autora menciona também a importância de se estimular a criatividade como aliada no trabalho do tradutor (cf. KUSSMAUL, 1995).

Como formas de se desenvolver a identidade social e profissional do tradutor durante a formação, Colina argumenta que se deve propiciar um feedback social rico, com vários agentes de monitoramento (além do professor), utilizando-se de tarefas autênticas, possibilitando o contato com profissionais, através de estágios, eventos acadêmicos e científicos da área, dentre outras. Nas tarefas de tradução em sala, é destacada a importância dos briefs, que servem para delimitar a produção do texto-alvo em um contexto real e comunicativo, fazendo com que a tradução supere a noção ingênua, que muitos aprendizes têm, de mera atividade de transferência linguística.

Tendo em vista a usual inserção dos cursos de tradução em departamentos ou institutos de letras e ensino de línguas, inserção essa que também é muito comum no contexto acadêmico no Brasil, a autora observa que a área de formação de tradutores empresta muitos aspectos teóricos, metodológicos e didático-pedagógicos do ensino de línguas. Assim, em comum com o ensino-aprendizagem comunicativo de línguas estrangeiras, a abordagem da formação de tradutores como atividade comunicativa procura situar a tradução como um fenômeno que se constitui no contexto interacional. De forma análoga, uma abordagem formalista dos fenômenos linguísticos acaba também sendo transposta para a tradução, que, então, é vista como mera transferência semântica descontextualizada. 
No Capítulo 3, Planejamento do curso, a autora traz propostas para possíveis aplicações em cursos com abordagem comunicativa/funcionalista, de caráter geral e introdutório, retomando questões dos capítulos anteriores e aplicando-as à sala de aula. Com base em House (1980), descreve-se um cenário tradicional de aula de tradução, em que o professor define o padrão a ser seguido nas escolhas tradutórias. No modelo de ensino comunicativo, o professor passa a ser um colaborador e o aluno passa a ser o centro do processo, interagindo não só com o professor, mas também com outros colegas. Apesar de não ser o centro, o professor é responsável pelo direcionamento das atividades e também deve certificar-se de que o relativismo na interpretação dos textos traduzidos não pode justificar qualquer escolha, havendo limites para a variabilidade de interpretações.

Na seção intitulada "Componentes do curso", comenta-se como vem mudando o contexto de trabalho do tradutor, cada vez mais integrado e em cooperação com outros colegas, mesmo distantes, através da internet. Entretanto, os recursos tecnológicos são apoios e, ainda que essenciais, não devem tornar-se o foco principal da formação, questão a ser considerada com bastante cuidado especialmente na atualidade, dado o desenvolvimento de novas ferramentas e tecnologias à disposição do tradutor. Em outros termos, estamos cada vez mais dependentes das tecnologias de apoio à tradução, mas elas, definitivamente, não constituem o cerne da competência tradutória.

Com relação a expor os alunos a contextos tradutórios autênticos, isso nem sempre é fácil ou mesmo viável. Nesse sentido, a autora sugere atividades de interação via e-mail, importantíssimas para o desenvolvimento do processo de socialização profissional da tradução, o que hoje deve ser complementado e expandido através das diversas redes sociais digitais que podem viabilizar o contato com diversos agentes da área de tradução e, assim, impulsionar a integração com o contexto profissional.

São também discutidos no Capítulo 3 aspectos como: participação em sala de aula (com a finalidade de se desenvolver autoconfiança, autoconsciência e profissionalismo), as possíveis formas de avaliá-la, a relevância da inserção do ensino teórico (não necessariamente da teoria de tradução, mas dos muitos pressupostos teóricos relacionados às questões linguísticas, discursivas e culturais), a necessária vinculação das teorias às questões práticas e pedagógicas, além do uso de diversas ferramentas de tradução (hoje muito voltadas para as ferramentas e aplicativos computacionais, mas que, como mencionado acima, não devem se tornar o centro do processo de ensino-aprendizagem). Além desses aspectos, a autora também sugere o 
portfólio como um instrumento didático-pedagógico importante para o acompanhamento do desenvolvimento da competência tradutória e para a priorização da avaliação do processo de aprendizagem em relação ao produto. Sugere que as teorias sejam contextualizadas na última fase de qualquer unidade, permitindo assim que sejam também assimiladas de forma significativa. Com relação aos processos de revisão na tradução, Colina comenta que os aprendizes costumam não lhe dar a devida atenção, sendo necessário incorporá-los à formação. Por fim, trata-se do projeto de tradução como uma metodologia pedagógica importante para a formação, enfatizando-se que, através dessa metodologia, os alunos aprendem a lidar com aspectos concretos do trabalho e a organizar projetos de longo prazo.

No final do capítulo, é apresentado um exemplo de programa de curso ou plano de ensino para uma disciplina introdutória de tradução, de forma bastante aberta para que possa ser aplicada/adaptada para um contexto de ensino-aprendizagem. Obviamente, a definição do que poderá ser efetivamente adotado e/ou adaptado dependerá das definições do desenho curricular e de seu contexto de implantação, uma vez que é preciso analisar os diversos componentes curriculares para se avaliar o seu potencial de contribuição para o desenvolvimento da competência tradutória.

No Capítulo 4, Elaboração de materiais didáticos, são discutidas propostas de criação de materiais didáticos com base nas questões teóricas e pedagógicas discutidas anteriormente. O roteiro das atividades é apresentado com vistas especialmente a estimular e desenvolver a autoconscientização e a postura profissional, enfatizando o debate de posições e a criatividade, características embasadas em teorias socioconstrutivistas (KIRALY, 2000; VYGOTSKY, 1962; 1971, 1978). São sugeridas as seguintes fases para as tarefas de tradução: atividades de pré-tradução, tradução, discussão no foco linguístico e atividades de pós-tradução. Ao longo do capítulo, são apresentadas e discutidas as possibilidades de aplicação dessas atividades em tarefas de tradução, com ampla e profunda reflexão sobre as diversas implicações. Como mencionado anteriormente, a discussão teórica é feita em fase posterior, além de ser também incluso na sistematização um tópico sobre ferramentas de tradução. Apesar de as diversas fases e elementos da composição dos materiais e das atividades didáticas serem destacados em separado, sua aplicação demonstra uma integração e articulação bastante coerente, servindo de base para unidades didáticas no ensino de tradução em diversificados contextos.

O Capítulo 5, Avaliação e erros, aborda diversos aspectos da avaliação. Com base nas discussões da pedagogia, a autora ressalta a diferença entre avaliação do produto e do processo. 
Para o ensino-aprendizagem, é fundamental avaliar o processo, ainda que haja limitações para isso. Colina menciona que não existe efetivamente uma base sistemática para avaliação - os critérios de avaliação costumam ser arbitrários, priorizando-se muito mais aspectos da compreensão do que propriamente da competência tradutória. Nesse particular, Kussmaul (1995) é citado como alternativa, propondo um tipo de abordagem comunicativa para a avaliação na tradução. Também se destaca a importância da avaliação formativa, além da somativa, cujo foco se concentra nas características do produto. A avaliação do processo nem sempre é simples ou alcançada de forma direta, por isso, a autora ressalta a importância de se avaliarem os diversos componentes da competência tradutória, que é o objetivo do ensino de tradução. No entanto, para se pensar na avaliação dessa competência, é preciso ter clareza sobre a sua definição e composição e quais os materiais didáticos e instrumentos serão aplicados. A autora concorda com o caráter multicomponencial dessa competência, o que tem sido consensual nos trabalhos sobre o tema. É importante mencionar hoje o modelo PACTE (2003, 2014), que incorpora aspectos cognitivos e sociointerativos da atividade tradutória e vem sendo bastante discutido e testado em contextos de pesquisa e de ensino-aprendizagem de tradução, inclusive no Brasil, o que, em grande medida, procura minimizar a limitação apontada por Colina em relação à falta de validação empírica para muitos modelos propostos até então.

Na seção intitulada “A avaliação, o programa e o currículo", ressalta-se a importância da avaliação no processo de aprendizagem e a necessidade de se pensarem testes que não avaliem somente a proficiência linguística, como tem sido habitual, mas, especialmente, elementos da competência tradutória. Com relação ao formato dos testes, Colina aponta a necessidade de se observarem alguns parâmetros para a eficácia de sua elaboração, quais sejam: objetivos claros, definição das habilidades a serem avaliadas, economia, relevância, aceitabilidade e comparabilidade, definição precisa dos critérios de pontuação, além de convergência em relação aos briefs fornecidos. São apresentados quadros relacionando parâmetros para a definição de critérios de pontuação na avaliação tanto do produto quanto do processo, distinguindo diferentes níveis de segmentação textual e contextual. Expandido essa proposta, a autora apresenta uma relação de parâmetros para a elaboração de critérios de avaliação para a tradução comunicativa, cuja pontuação se baseia nos trabalhos de Hatim e Mason (1997) e Cao (1996).

Com relação ao processo de revisão, a autora pondera que é difícil avaliá-lo em contextos de produção em que não haja registro do processo. A título de atualização, além dos 
protocolos verbais, mais recentemente se encontram disponíveis diferentes ferramentas que propiciam maior aproximação do processo, inclusive do de revisão. Exemplos são: o software Translog (JAKOBSEN, 1999), que registra em tempo real toda a produção textual na tradução; os recursos de rastreamento ocular, que permitem o mapeamento detalhado dos processos de leitura (CARL, 2012); e as interfaces de gravação/monitoramento de vídeo, como o Camtasia e o Proxy, vastamente descritos em pesquisas voltadas para a investigação dos processos cognitivos e da competência tradutória (PACTE, 2014).

Finalmente, cabe destacar que o trabalho ora resenhado representa importante contribuição, somando-se a produções no ramo dos estudos aplicados à didática da tradução, atendendo tanto a demandas do campo da pesquisa quanto ao das atividades didáticas e paradidáticas, indo ao encontro da sistematização e consolidação do ensino da tradução.

\section{Referências}

ALVES, F.; MAGALHÃES, C.; PAGANO, A. (Ed.). Traduzir com autonomia: estratégias para o tradutor em formação. São Paulo: Contexto, 2000.

ALVES, F.; GONÇALVES, J. L. Modelling translator's competence: relevance and expertise under scrutiny. In: GAMBIER, Y.; SCHELENSIGER, M.; STOLZE, R. (Ed.). Translation studies: doubts and directions. Amsterdã: John Benjamins, 2007. p. 41-55. http://dx.doi.org/10.1075/btl.72.07alv

ALVES, F.; GONÇALVES, J. L. V. R. Investigating the conceptual-procedural distinction in the translation process: a relevance-theoretic analysis of micro and macro translation units. Target, n. 25, v. 1, p. 107-124, 2013.

BASTIN, G. L.; CORMIER, M. C. Profession traducteur. Montreal: Les Presses de l’Université de Montréal, 2007.

CAO, D. A model of translation proficiency. Target, v. 8, n. 2, p.325-340, 1996. http://dx.doi.org/10.1075/target.8.2.07cao

CARL, M. Translog-II: a program for recording user activity data for empirical reading and writing research. In: International Conference on Language Resource and Evaluation, 8., 21-27 maio, 2012, Istambul. Proceedings... 4108-4122. Istambul: European Language Resources Association, 2012a. p. 4108-4122.

GALÁN-MAÑAS, A.; HURTADO ALBIR, A. Blended learning in translator training. Methodology and results of an empiric validation. The Interpreter and Translator Trainer (ITT), v. 4, n. 2, p. 197-231, 2010. http://dx.doi.org/10.1080/13556509.2010.10798804

HATIM, B.; MASON, I. The translator as communicator. Nova York: Routledge, 1997. 
HOLZ-MÄNTTÄRI, J. Translatorisches Handeln. Helsinki: Suomalainen Tiedeakatemia, 1984.

HOUSE, J. Übersetzen in Fremdsprachenunterricht. In: POULSEN, S. O.; WILSS, W.(Ed.). Angewandte Übersetzungwissenschaft. Arhus: Wirtschaftsuniversität Arhus, 1980. p. 7-17.

HURTADO ALBIR, A. Traducción y traductología: introducción a la traductología. Madri: Cátedra, 2001.

HURTADO ALBIR, A. competence-based curriculum design for training translators. The Interpreter and Translator Trainer (ITT), v. 1, n. 2, p. 163-195, 2007. http://dx.doi.org/10.1080/1750399X.2007.10798757

HURTADO ALBIR, A. Competence en traduction et formation par competences. TTR: Traduction, Terminologie, Redaction, v. 21, n. 1, p. 17-64, 2008.

HURTADO ALBIR, A. The acquisition of translation competence. Competences, tasks, and assessment in translator training. Meta, Montreal, v. 60, n. 2, p. 256-280, 2015. http://dx.doi.org/10.7202/1032857ar

JAKOBSEN, A. L. Logging target text production with Translog. In: HANSEN, G. (Ed.). Probing the process in translation: methods and results. Copenhagen: Samfundslitteratur, 1999. p. 9-20.

KELLY, D. A handbook for translator trainers. Manchester: St. Jerome, 2005.

KIRALY, D. A role for communicative competence and the acquisition-learning distinction in translator training. In: VANPATAEN, B.; LEE, J. (Ed.). Second language acquisition / foreign language learning. Bristol: Multilingual Matters, 1990. p. 207-215.

KIRALY, D. Pathways to translation. Kent: Kent State University Press, 1995.

KIRALY, D. A social constructivist approach to translator education. Manchester: St. Jerome, 2000.

KUSSMAUL, P. Training the translator. Amsterdã: John Benjamins, 1995. http://dx.doi.org/10.1075/btl.10

NORD, C. Scopos, loyalty and translational conventions. Target, v. 3, n. 1, p. 91-109, 1991. http://dx.doi.org/10.1075/target.3.1.06nor

NORD, C. Translating as a purposeful activity: functionalist approaches explained. Manchester: St. Jerome, 1997.

PACTE. Building a translation competence model. In: ALVES, F. (Ed.). Triangulating translation: perspectives in process oriented research. Amsterdã: John Benjamins, 2003. p. 4366. 
PACTE. First results of PACTE Group's experimental research on translation competence acquisition: the acquisition of declarative knowledge of translation. MonTI Special Issue Minding Translation, p. 85-115, 2014.

PAGANO, A.; MAGALHÃES, C.; ALVES, F. (Org.). Competência em tradução: cognição e discurso. Belo Horizonte: Ed. UFMG, 2005.

REISS, K.; VERMEER, H. J. Grundlegung einer allgemeinen Translationstheorie. Tübingen: Niemeyer, 1984. http://dx.doi.org/10.1515/9783111351919

SHREVE, G. Cognition and the evolution of translation competence. In: DANKS, J.; SHREVE, G. M.; FOUNTAIN, S. B.; McBEATEH, M. K. (Ed.). Cognitive processes in translation and interpreting. Thousand Oaks: Sage, 1997. p. 120-136.

VYGOTSKY, L. S. Thought and language. Cambridge: MIT Press, 1962. http://dx.doi.org/10.1037/11193-000

VYGOTSKY, L. S. The psychology of art. Cambridge: MIT Press, 1971.

VYGOTSKY, L. S. Mind in society. The development of higher psychological processes. Cambridge: Harvard University Press, 1978. 